\title{
EDUGAMES N-RAM UNTUK PEMBELAJARAN GEOMETRI PADA ANAK USIA DINI
}

\author{
Taufik Ridwan"), Endang Hidayat ${ }^{2)}$ Zaenal Abidin $^{3)}$

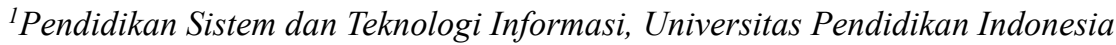 \\ ${ }_{2}^{2}$ Pendidikan Guru Sekolah Dasar, Universitas Pendidikan Indonesia \\ ${ }^{3}$ Sistem Informasi, Universitas Teknokrat Indonesia \\ ${ }^{1,2} \mathrm{Jl}$. Veteran no. 8 Purwakarta, Indonesia



\begin{abstract}
The development and growth in children must be stimulated properly. In general, children have the ability to learn and a high curiosity. They tend to like games that attract attention to be played. This research presents a prototype of Digital Edu Games s for children that can be used in helping to learn geometry based on specific problem solving approaches. The method used in this research is Research and Development $(R \& D)$ with a waterfall approach in software development. The objectives of this study are: (1) analyzing game's needs for learning geometry for children; (2) designing and building $N$-Ram for children with specific case-based problem solving. This research has the benefit of developing learning media through Digital Edu Games that are combined with games in the form of games in gadgets. The results of this research are to create digital games based on digital game early childhood learning that needs to be done in-depth analysis of the needs and interests of children to be able to play the digital game. The design of the game can attract the attention of children, this can be seen from the look of the N-Ram user interface which is quite colorful. Game's N-Ram can be used as a medium of entertainment as well as a learning medium for children in learning geometry.
\end{abstract}

Keyword : digital games, learning media, geometry, children

\begin{abstract}
Abstrak
Perkembangan dan pertumbuhan pada anak harus distimulasi dengan baik. Pada umumnya anak mempunyai kemampuan belajar dan rasa ingin tahu yang tinggi. Mereka cenderung menyukai permainan hal yang menarik perhatian untuk dimainkan. Penelitian ini menghadirkan sebuah prototype Digital Edu Game s untuk anak yang dapat digunakan dalam membantu belajar geometri berbasis pendekatan pemecahan masalah tertentu. Metode yang digunakan dalam penelitian ini adalah Research and Depelovment $(R \& D)$ dengan pendekatan waterfall dalam pembangunan perangkat lunak. Tujuan dari penelitian ini adalah: (1) menganalis kebutuhan game s untuk pembelajaran geometri untuk anak; (2) merancang dan membangun N-Ram untuk anak dengan pemecahan masalah berbasis kasus tertentu. Penelitian ini memiliki kebermanfaatan dalam pengembangan media pembelajaran melalui Digital Edu Game s yang dipadu dengan permainan dalam bentuk game s di gadget. Hasil dari peneltian ini adalah untuk membuat media pembalajaran anak usia dini berbasis digital game s yang perlu dilakukan analisis mendalam mengenai kebutuhan dan ketertarikan pada anak untuk dapat bermain game s digital tersebut. Desain dari game s dapat menarik perhatian anak-anak, hal ini dapat dilihat dari tampilan user interface N-Ram yang cukup berwarna. Game s N-Ram dapat dijadikan sebagai media hiburan sekaligus media pembelajaran untuk anak-anak dalam belajar geometri.
\end{abstract}

Kata Kunci: digital games, media pembelajaran, geometri, anak

\section{Pendahuluan}

Perkembangan dan pertumbuhan pada anak usia dini harus distimulasi dengan baik agar dapat terjadi secara optimal. Pada fase ini sering disebut dengan fase emas (golden age) tumbuh kembang. Salah satu perkembangan yang harus distimulasi adalah perkembangan kognitif dengan mengenalkan benda-benda yang ada di sekitar anak. Dalam tumbuh kembangnya, anak tidak dapat dipisahkan dari benda-benda yang ada di sekitar dalam bermain. Sejak kecil mereka sudah mengenal benda-benda disekitar dengan beraneka bentuk dan ragam termasuk bentuk geometri, misalnya koin, lemari, meja, buku, bola, atau benda lainnya yang digunakan untuk memenuhi kebutuhan dalam kehidupan sehari-hari untuk keperluan bermain[1].

Geometri merupakan bagian dari matermatika yang mempelajari konsep bentuk dan ruang. Freudenthal menyebutkan bahwa geometri adalah ruang dimana anakanak berada, hidup dan bergerak. Dalam ruang itu anak harus belajar mengetahui (to know), menelaah (to explore), bertempur untuk menang (conquer), merencanakan dan mengatur kehidupan (in order to live), bernafas (breathe) dan berbuat yang lebih baik (move better in it)[2]. 
Beberapa alasan mengapa geometri perlu diajarkan kepada anak diantaranya adalah pertama, geometri satusatunya bidang matematika yang dapat mengaitkan matematika dengan bentuk fisik dunia nyata. Kedua, geometri satu-satunya yang dapat memungkinkan ide-ide matematika yang dapat divisualisasikan, dan yang ketiga, geometri dapat memberikan contoh yang tidak tunggal tentang sistem matematika[3].

Mengenalkan bentuk-bentuk geometri pada anak usia dini dapat dimulai dari membangun konsep geometri yaitu dengan mengidentifikasi ciri-ciri bentuk geometri[4] Triharso menyatakan bahwa kemampuan dalam mengenal bentuk geometri pada anak selalu berkaitan dengan pembelajaran matematika. Matematika di PAUD adalah kegiatan belajar tentang konsep matematika melalui aktivitas bermain dalam kehidupan sehari-hari dan bersifat ilmiah. Belajar sekaligus bermain merupakan salah satu cara yang dapat digunakan untuk pembelajaran matematika geometri pada anak[5]. Menurut teori Bloomada enam jenjang proses dalam berpikir, diantaranya adalah mengetahui, memahami, menerapkan, menganalisis, mengevaluasi, dan berkreasi[1].

Penelitian permainan untuk pembelajaran matematika sebenarnya sudah pernah dilakukan. Itawari melakukan penelitian yang menyimpulkan melalui permainan tangram dapat mengembangkan kreativitas anak usia dini pada TK FKIP Unsyiah Banda Aceh[6]. Selain itu, Liu meneliti penggunaan permainan dimana terjadi peningkatan kemampuan anak-anak dalam pembelajaran matematika dengan disertai aktivitas bermain dibandingkan dengan cara pembelajaran konvensional didalam kelas[7].

Perkembangan teknologi yang pesat telah mempengaruhi anak dengan bermain. Pada fase tumbuh kembang ini, anak-anak menghabiskan sebagian besar waktunya untuk bermain. Anak pada umumnya mempunyai kemampuan belajar dan rasa ingin tahu yang sangat tinggi. Mereka cenderung menyukai permainan yang menarik perhatian untuk dimainkan. Hadirnya gadget telah menarik perhatian anak untuk mencoba dan bahkan menjadi pengguna aktif. Gadget menyajikan wadah yang dipenuhi ragam multimedia di dalam satu perangkat. Sajian lengkap ini tidak didapatkan oleh anak pada media lain, sehingga kecenderungan untuk menyukai gadget sangat tinggi. Dampaknya, tidak jarang anak-anak lebih suka bermain gadget daripada melakukan aktivititas lain termasuk belajar. Hal yang paling parah adalah membuat anak menjadi kecanduan game s. Pada masa bermain ini, sebenarnya dapat dimanfaatkan untuk mengenalkan permainan yang mengandung nilai pembelajaran. Hal ini dapat dilkakukan salah satunya dengan penggunaan teknologi.

Perlu dicari pendekatan yang dapat membantu anak untuk lebih bijak dalam menggunakan gadget. Salah satunya adalah permainan digital yang dapat merangsang kecerdasan anak. Hal inilah yang akhirnya memunculkan ide bagaimana membuat anak menjalani proses belajar dalam kegiatan bermain, sehingga anak akan tetap mendapatkan hiburan melalui suatu media yang menarik dan menyenangkan.
Vitianingsih kemudian mengkaji penelitian terkait game edukasi yang dapat membantu pembelajaran. Game edukasi ini dapat membantu guru dan siswa PAUD dalam mengubah cara belajar konvensional menjadi cara belajar simulasi dengan media game dan memudahkan siswa PAUD untuk belajar mengenal simbol, berhitung, mencocokkan gambar dan menyusun acak kata[8]

Dari kedua penelitian sebelumnya[6,7], kedua permainan yang diteliti adalah permainan konvensional. Permainan geometri di playstrore android sebenarnya juga sudah ada. Salah satunya adalah permainan tangram dalam berbagai versi. Namun dari beberapa game s tangram yang tersedia di playstore kebanyakan tangram yang bersifat umum bahkan lebih cocok dimainkan untuk orang dewasa bukan dikhususkan kepada anak usia dini. Hal ini didasari kesulitan yang cukup rumit dalam bermain dan menyelesaikan game s yang tersedia tersebut. Salah satu yang dapat dijadikan solusi adalah tersedianya permainan geomteri anak yang bermanfaat dan sesuai tingkat kesulitannya dengan umur pemainnya.

Penelitian ini mencoba memeberikan alternatif solusi berupa game s digital untuk membantu anak belajar. Anak dapat merasakan kesenangan sambil belajar secara bersamaan. Penelitian ini akan mencoba menyediakan media untuk belajar dimulai dari fase mengetahui, mengenal, hingga menerapkan bentuk geometri.

Permainan N-ram yang dirancang adalah permainan yang memanfaatkan kolaborasi pembelajaran sains dengan teknologi yang dipadu padankan dengan matematika atau yang lebih dikenal dengan STEM. NRam yang dipadukan dengan STEM ini harus menghasilkan sebuah media belajar anak yang menyenangkan dengan berbasis kasus tertentu.

\section{Tinjauan Pustaka}

Permainan N-ram yang dirancang adalah permainan yang memanfaatkan kolaborasi pembelajaran sains dengan teknologi yang dipadu padankan dengan matematika atau yang lebih dikenal dengan STEM. NRam yang dipadukan dengan STEM ini harus menghasilkan sebuah media belajar anak yang menyenangkan dengan berbasis kasus tertentu.

Matematika merupakan disiplin ilmu logika untuk menguasai bentuk, susunan,besaran, dan konsep-konsep yang berhubungan satu sama lainnya dengan jumlah yang banyaknya terbagi ke dalam tiga bidang pokok, yakni aljabar, analisis, geometri. Matematika merupakan salah satu ilmu yang banyak dimanfaatkan dalam kehidupan sehari-hari. Baik secara umum maupun secara khusus. Hampir di setiap aspek kehidupan ilmu matematika dapat diterapkan.

Geometri mempunyai arti harfiah yaitu pengukuran bumi. Geometri adalah bagian dari matematika yang membahas mengenai titik, garis, bidang, dan ruang. Ruang adalah himpunan titik-titik yang dapat membentuk bangun-bangun geometri, garis adalah himpunan bagian dari ruang yang merupakan himpunan titik-titik yang mempunyai sifat khusus. Bidang adalah himpunan- 
himpunan titik-titik yang terletak pada permukaan datar[9].

Pembelajaran geometri pada usia dini dimungkinkan untuk diajarkan walaupun harus dengan cara yang lebih kreatif dan realistik. Geometri dianggap mempunyai banyak aplikasi dalam matematika dan kehidupan nyata, yang juga banyak mengandung unsur problem solvingnya. Pembelajaran matematika khususnya geometri untuk anak usia dini bertujuan untuk mengenal, menunjuk, menyebutkan serta mengumpulkan benda-benda di sekitar berdasarkan bentuk geometri. Tahap pertama anak belajar geometri adalah topologis. Mereka belum mengenal jarak, kelurusan dan yang lainnya, karena itu mulai belajar geometri supaya tidak mulai dengan lurus- lurus, tetapi denga lengkung, misalnya lengkungan tertutup, lengkungan terbuka daerah lengkungan, lengkungan sederhana dan lainnya. Mengutip Van Hiele dalam Ruseffendi[10] berpendapat bahwa ada lima tahapan anak belajar geometri, yaitu pengenalan,analisis, pengurutan, dedukasi, dan keakuratan.

Dalam permainan matematika terdapat permainan yang bernama tangram. Permainan ini yaitu suatu permainan puzzle persegi yang dipotong menjadi 7 bagian ( 2 berbentuk segitiga besar,1 berbentuk persegi, 1 berbentuk jajarangenjang, 1 berbentuk segitiga sedang, dan 2 berbentuk segitiga kecil).

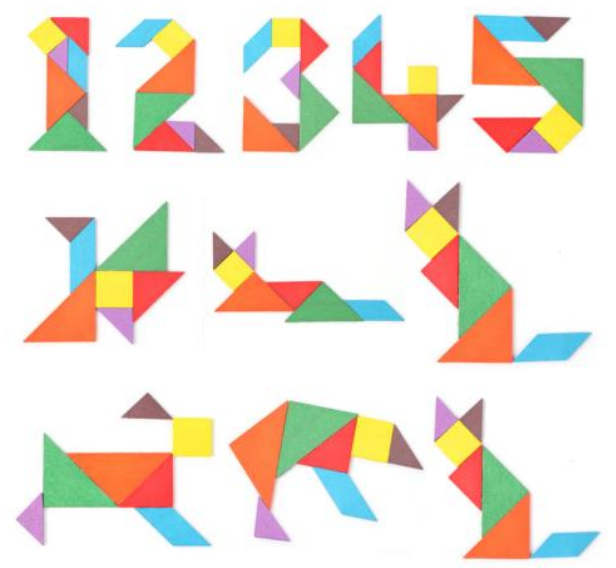

Gambar 1. Contoh Tangram

Cara permainan tangram ini juga tergolong mudah dan dirancang dengan penggunaan yang sesuai untuk anak pada usia 4-7 tahun. Ketika bermain, sang anak akan menebak dan mencoba-coba bentuk potongan yang digabungkan menjadi satu pola besar berbentuk benda disekitar. Hal ini akan memancing rasa ingin tahu anak untuk terus berkreasi sekaligus memacu kognitif anak untuk mengenal benda-benda disekitar.

\section{Metode Penelitian}

Metode yang digunakan dalam penelitian ini adalah Research and Depelovment (R\&D). Penelitian ini bermaksud untuk menggabungkan pembelajaran yang menyenangkan dengan perkembangan teknologi. Keluaran dari penelitian akan dihasilkan sebuah prototype produk game untuk proses membantu pembelajaran geometri untuk anak-anak.

Dalam tahapan yang dilakukan dalam pembuatan game menggunakan metode R\&D ini, digunakan metode perancangan perangkat lunak yang bernama waterfall. Tahapan yang dilalui dengan waterfall akan berguna untuk dapat menghasilkan perangkat lunak yang handal dan efektif. Metode ini merupakan metode dalam perancangan lunak yang dimulai dari fase analisis hingga perangkat lunak dapat dioperasikan[11]. Proses pembuatan perangkat lunak yang dilalui adalah fase analisis kebutuhan, peracangan, pembuatan program (pengkodean), pengujian, hingga pengoperasian perangkat lunak.

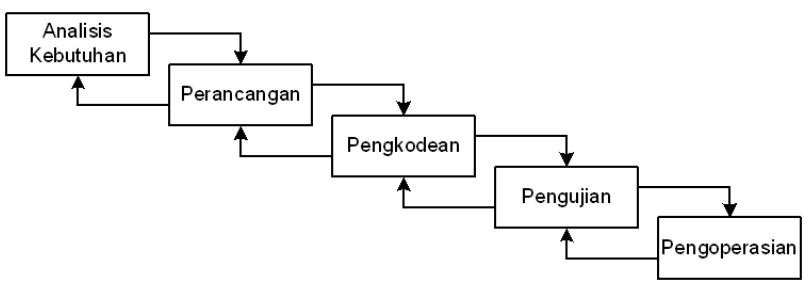

Gambar 2. Diagram alur waterfall dalam pembangunan perangkat lunak

Kelima fase pada Gambar 2 harus dilalui dengan baik. Setiap satu fase akan berpengaruh kepada fase setelahnya yang pada akhirnya akan menghasilkan sebuah games digital. Game merupakan salah satu media yang cukup menyenangkan untuk proses pembelajaran. Namun kenyataan yang ada justru sebaliknya. Pasar game hari ini justru banyak diisi oleh game yang kontennya banyak menyajikan unsur kekerasan sebagai unsur utamanya. Tentu saja, hal tersebut dapat menimbulkan pengaruh yang negatif pada tumbuh kembang anak. Untuk dapat membuat game yang dapat meningkatkan kemampuan geometri anak berbasis pemecahan masalah.

\section{Implementasi dan Hasil}

Sistem yang sebelumnya dilakukan analisis dan desain, kemudian dilakukan langkah selanjutnya yakni implementasi untuk menjadikan sistem dapat dioperasikan seutuhnya. Sistem ini berbasis mobile dikembangkan menggunakan bahasa pemrograman $\mathrm{C \#}$ menggunakan kakas unity.

Pada implementasi, ada hal yang harus diperhatikan yaitu mempersiapkan semua infrastruktur yang dibutuhkan untuk pengujian sistem. Perangkat keras yang digunakan pada proses pengujian adalah Handpohone dengan sistem operasi android dengan jenis sistem operasi minimal android kit kat.

Games yang dibuat dalam penelitian ini berbasis mobile. Games dijalankan dalam sebuah sistem operasi android. Ketika pemain bermain, pemain harus melakukan perintah yang diberikan per level nya. Pemain akan melakukan klik gambar atau menggeser potongan puzzle. Semakin tinggi level permainan, maka tingkatan permainan juga semakin sulit dan waktu yang disediakan sistem juga semakin sedikit.

Games dirancang dua layar utama yakni antarmuka awal permainan, dan antarmuka pada permainan inti. Pada 
tahap ini, dibuat rancangan arsitektur sistem yang akan dibangun

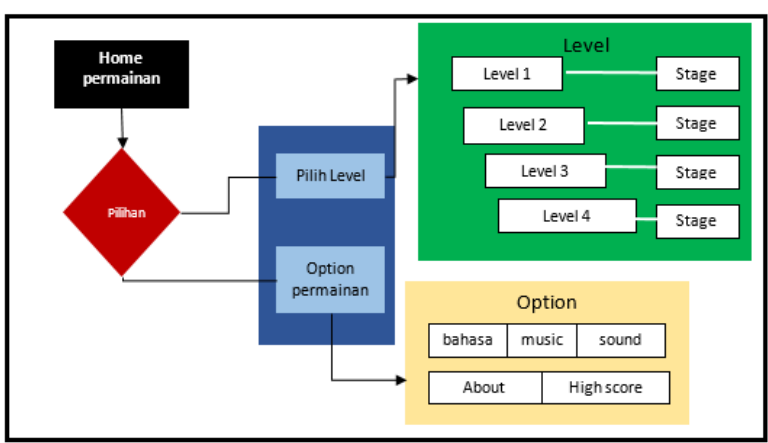

Gambar 3. Rancangan arsitektur sistem

Pada Gambar 3 dapat dilihat games berisi dua pilihan yakni memilih level yang kemudian akan memulai permainan, dan option yang digunakan pengaturan permainan. Dari arsitektur tersebut juga terlihat games ini cukup namun setiap levelnya akan disesuaikan dengan tingkatan kesulitan tertentu.

Implementasi perangkat lunak merupakan hasil proses pengkodean yang berupa perangkat lunak yang siap digunakan. Adapun tampilan awal dari games ini adalah sebagai berikut:
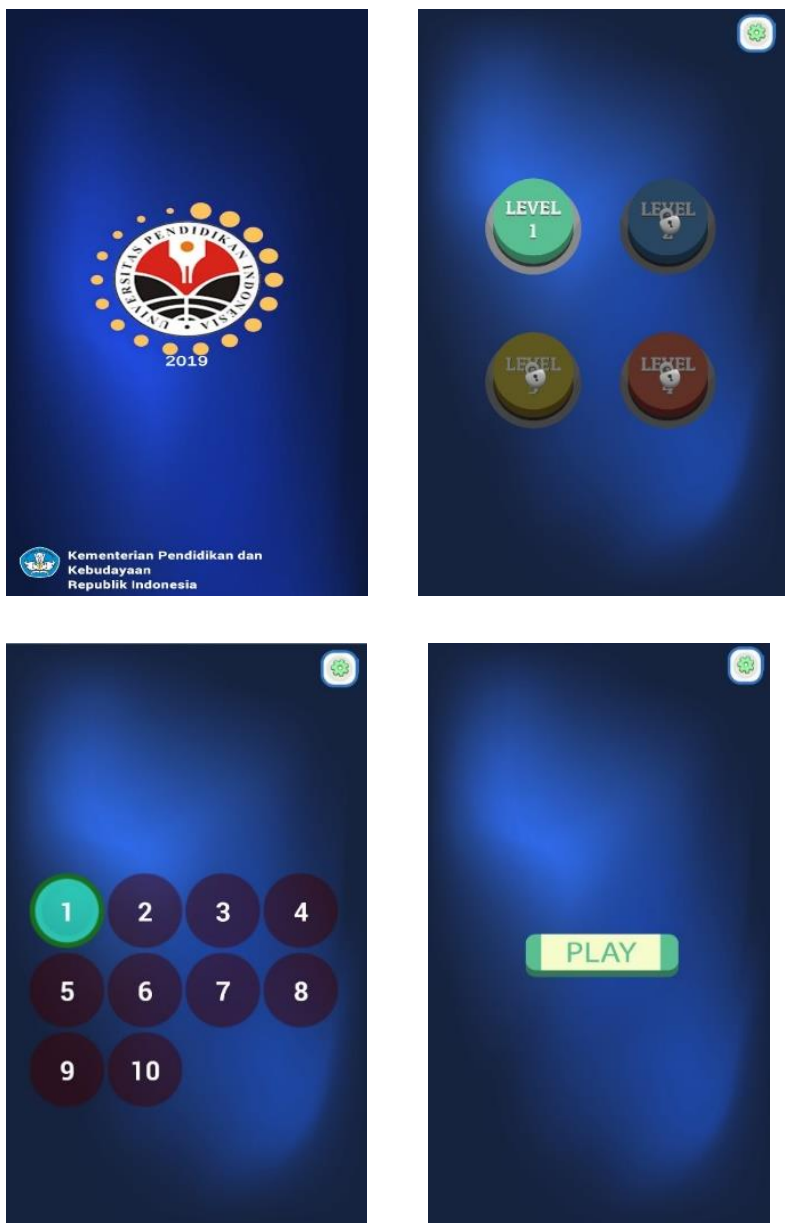

Gambar 4. Tampilan awal dari N-Ram
Dari Gambar 9 dapat dilihat tampilan awal dari NRam mulai dari splash screen, pemilihan level, stage, hingga akan memulai games ini. Selanjutnya adalah implementasi games per level sebagai berikut:
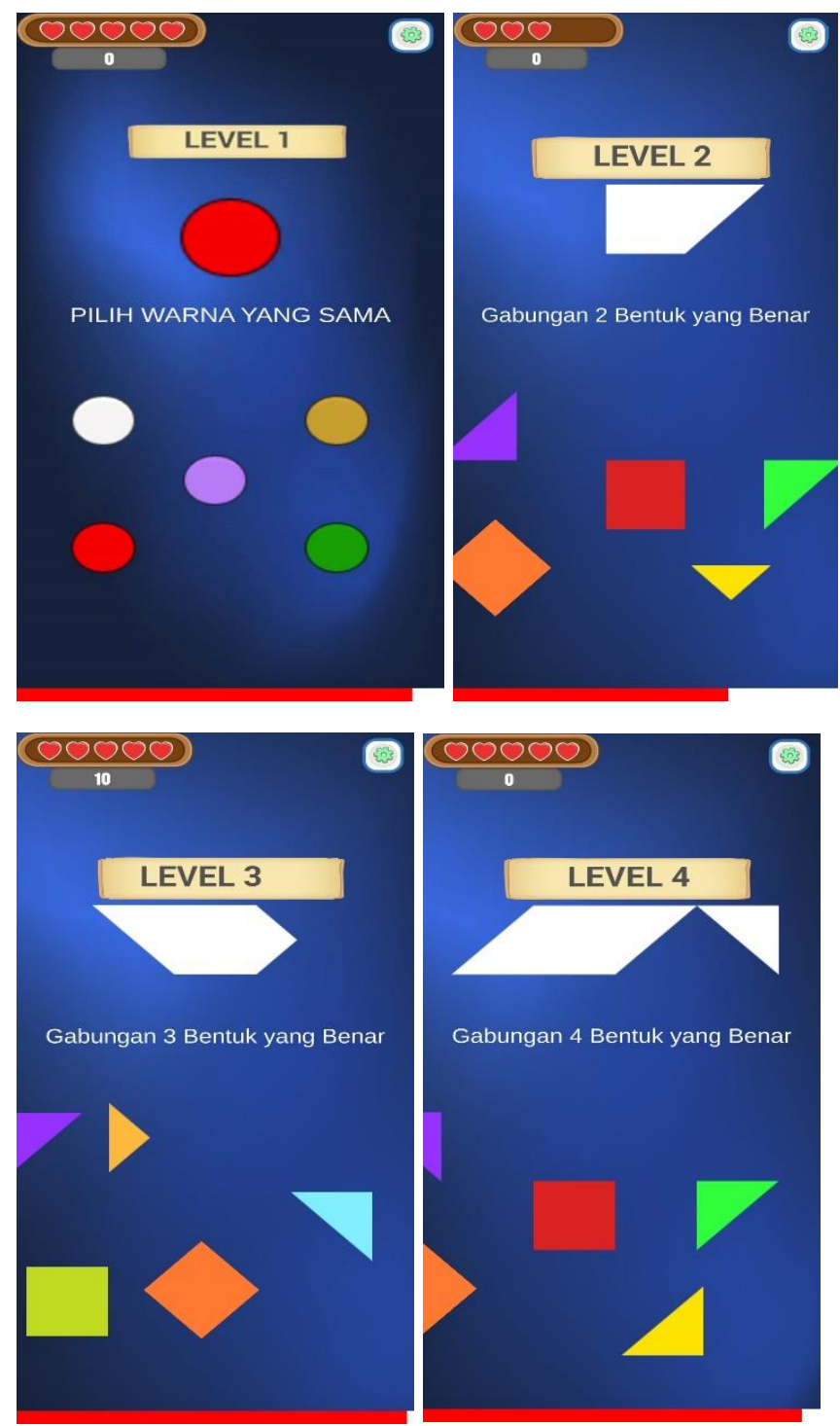

Gambar 5. Tampilan N-Ram per levelnya

Pada dasarnya user atau pemain dalam memainkan games ini harus meyelesaikan tantangan yang diberikan pada setiap level dan babak permainan. Pada setiap level permainan akan berubah tingkat kesulitannya disesuaikan dengan semakin tingginya level permainan. Pada level 1 ini disediakan permainan yang mengharuskan user untuk memilih warna yang cocok sesuai pertanyaan yang disediakan. Pada level ini pemain tinggal melakukan klik warna yang sesuai. Pada level 2 pemain diharuskan menyusun gambar yang sesuai sesuai potongan yang tersedia. Level 3 pemain harus menyusun gambar yang lebih banyak daripada level 2. Pada level ini level permainan diarahkan sedikit lebih sulit daripada level sebelumnya. Pada level 4 pemain diarahkan untuk menyusun gambar yang lebih kompleks daripada levellevel sebelumnya. 
Proses pengujian dan pengoperasian perangkat lunak anak dimulai dengan menguji fungsionalitas dari rancangan yang dibangun. Pengujian dilakukan untuk menguji apakah perangkat lunak yang dihasilkan sudah dapat berfungsi atau belum sesuai dengan tahapan yang dilakukan pada fase-fase sebelumnya. Hasilnya adalah game yang bisa dioperasikan oleh anak. Subyek uji coba dalam penelitian ini diperuntukkan untuk pengujian aspek functionality dan usability. Subyek penelitian pada aspek functionality adalah orang yang ahli dalam bidang software engineering. Sedangkan pada aspek usability adalah siswa atau anak usia dini di aera Purwakarta.

Pengujian merupakan suatu proses pengeksekusian aplikasi yang bertujuan untuk menemukan kesalahan. Pengujian bertujuan untuk menemukan kesalahan yang tidak disengaja. pengujian dinyatakan sukses jika berhasil memperbaiki kesalahan tersebut. Selain itu, pengujian juga bertujuan untuk menunjukkan kesesuaian fungsifungsi perangkat lunak dengan spesifikasinya. Dari hasil analisis kebutuhan fungsionalitas perangkat lunak, kemudian diujikan terhadap sistem. Untuk mengetahui apakah sistem dapat bekerja dengan baik atau tidak. Berikut pengujian black box yang ditampilkan pada Tabel 1

Tabel 1. Pengujian fungsional

\begin{tabular}{|c|c|c|}
\hline Kode & Kelas Uji & Kelas Uji \\
\hline KF-01 & Memilih tiap level & $\begin{array}{l}\text { Pemain dapat memilih } \\
\text { level atau babak } \\
\text { permainan }\end{array}$ \\
\hline KF-02 & Masuk ke permainan & $\begin{array}{l}\text { Pemain dapat masuk ke } \\
\text { permainan }\end{array}$ \\
\hline \multirow[t]{2}{*}{ KF-03 } & $\begin{array}{l}\text { Reward dan } \\
\text { punishment selama } \\
\text { permainan }\end{array}$ & $\begin{array}{l}\text { Pemain mendapatkan } \\
\text { nilai tertentu apabila } \\
\text { menyelesaikan satu } \\
\text { tantangan (stage) } \\
\text { sampai selesai. }\end{array}$ \\
\hline & & $\begin{array}{l}\text { Pemain kehilangan hati } \\
\text { yang befungsi sebagai } \\
\text { nyawa apabila gagal } \\
\text { menyelesaikan } \\
\text { tantangan }\end{array}$ \\
\hline KF-04 & $\begin{array}{l}\text { Mencocokan bentuk, } \\
\text { warna, atau menyusun } \\
\text { fuzzle }\end{array}$ & $\begin{array}{l}\text { Gambar di soal dapat } \\
\text { dicocokan dengan yang } \\
\text { ada di jawaban }\end{array}$ \\
\hline KF-05 & $\begin{array}{l}\text { Tampil skor nilai } \\
\text { pemain }\end{array}$ & Skor muncul \\
\hline
\end{tabular}

Subyek uji coba dalam penelitian ini diperuntukkan untuk pengujian aspek functionality dan usability. Subyek penelitian pada aspek functionality adalah orang yang ahli dalam bidang software engineering. Hasil pengujian secara fungsional didapati perangkat lunak sudah berfungsi sesuai spesifikasi yang dibutuhkan. Pengujian pada aspek usability di SD Labschool UPI Kampus Purwakarta didapati anak cukup mudah untuk memainkan games ini, selain itu anak juga diasah kemampuan berpikir logisnya mengenai masalah geometri (keruangan) dengan cara yang menyenangkan. Pada pengujian anak cukup tertarik dan tertantang menyelesaikan persoalan yang diberikan pada N-Ram.

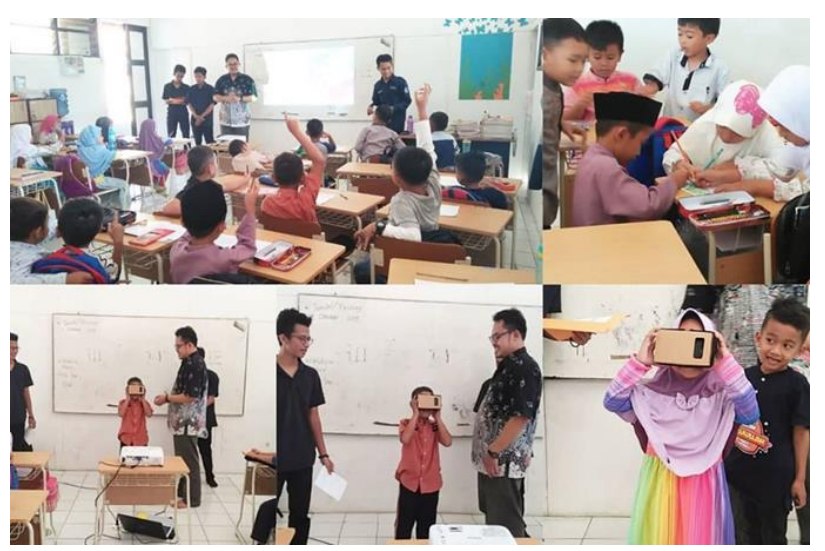

Gambar 4. Tampilan awal dari N-Ram

\section{Kesimpulan dan Saran}

Kesimpulan yang dapat diambil berdasarkan uraian yang telah dikemukan pada bab-bab sebelumnya adalah sebagai berikut

1. Untuk membuat media pembalajaran anak usia dini berbasis digital games perlu dilakukan analisis mendalam mengenai kebutuhan dan ketertarikan pada anak untuk dapat bermain games digital tersebut.

2. Desain dari games dapat menarik perhatian anak-anak, hal ini dapat dilihat dari tampilan user interface games yang cukup berwarna

3. Games N-Ram dapat dijadikan sebagai media hiburan sekaligus media pembelajaran untuk anak-anak dalam belajar geometri.

Dilihat dari games yang sudah dibangun, maka saran yang diajukan untuk pengembangan sistem ini, diantaranya :

1. Permainan untuk tiap levelnya dibuat lebih bervariasi

2. Permainan dapat digunakan untuk semua anak SD mulai dari dari kelas 1 sampai kelas 6

3. Sistem yang telah dibangun ini agar dapat dijadikan bahan untuk pengembangan sistem lebih lanjut. Dengan penyempurnaan di beberapa sisi penggunaan dari sistem ini akan menjadikannya lebih efektif dan digunakan

\section{Daftar Pustaka}

[1] Latif, Mukhtar, dkk. 2013. Pendidikan Anak Usia Dini.Jakarta : Kencana Prenada Media Group.

[2] Afgani, D. J. 2011. Analisis Kurikulum Matematika. Jakarta: Universitas Terbuka.

[3] Usiskin, Z.1982. Van Hiele Levels and Achievement in Secondary School Geometry. (Final report of the Cognitive Development and Achievement in Secondary School Geometry 
Project.) Chicago: University of Chicago. (ERIC Document Reproduction Service No. ED220288)

[4] Tedja Saputra, Mayke S. 2001. Bermain, Mainan dan Permainan. Jakarta: Grasindo

[5] Triharso, Agung (2013). Permainan Kreatif dan Edukatif untuk Anak Usia Dini. Yogyakarta: CV Andi Offset

[6] Itawari,Rizki. 2017. Penggunaan permainan tangram untuk mengembangkan kreativitas anak usia dini pada tk fkip unsyiah banda aceh. Skripsi Program Studi Pendidikan Guru Pendidikan Anak Usia Dini Universitas Syiah Kuala

[7] Liu, Yuting. 2014. Tangram Race Mathematical Game : Combining Wearable Technology and Traditional Game s for Enhancing Mathematics Learning. Worcester Polytechnic Institute

[8] Vitianingsih, A.V. (2016). Game Edukasi Sebagai Media Pembelajaran Pendidikan Anak Usia Dini. Jurnal INFORM, 1(1), 1-8

[9] Negoro. 2003. Ensiklopedia Matematika. Bogor: Ghalia Indonesia.

[10] Ruseffendi, E. T. Dkk. 1991. Pendidikan Matematika 3. Jakarta: Depdikbud.

[11] Pressman, R.S. 2010. Software Engineering: a practitioner's approach. New York: McGraw-Hill 